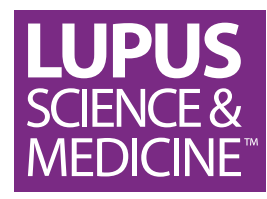

\title{
The ALPHA Project: Establishing consensus and prioritisation of global community recommendations to address major challenges in lupus diagnosis, care, treatment and research
}

\begin{abstract}
Karin Tse (D) , ${ }^{1}$ Sanjyot Sangodkar, ${ }^{2}$ Lauren Bloch, ${ }^{2}$ Kathleen Arntsen, ${ }^{3}$ Sang-Cheol Bae, ${ }^{4}$ lan N Bruce, ${ }^{5,6}$ Erin Connolly-Strong, ${ }^{7}$ Karen H Costenbader, ${ }^{8}$ Bradley Dickerson, ${ }^{9}$ Thomas Dörner (10 , ${ }^{10}$ Sydney Evans, ${ }^{11}$ Kenneth Kalunian, ${ }^{12}$ Amy H Kao, ${ }^{13}$ Susan Manzi, ${ }^{14}$ Eric F Morand, ${ }^{15}$ Sandra C Raymond (D) , 1 Brad H Rovin, ${ }^{16}$ Laura Eve Schanberg, ${ }^{17}$ Joan M Von Feldt, ${ }^{18}$ Victoria P Werth, ${ }^{19,20}$ Angel Williams Derricott, ${ }^{21}$ David Zook, ${ }^{2}$ Timothy Franson, ${ }^{22}$ Kenneth Getz, ${ }^{23}$ Yaritza Peña, ${ }^{23}$ Leslie M Hanrahan, ${ }^{1}$ On behalf of the ALPHA Project Global Advisory Committee
\end{abstract}

To cite: Tse K, Sangodkar S Bloch L, et al. The ALPHA Project: Establishing consensus and prioritisation of global community recommendations to address major challenges in lupus diagnosis, care, treatment and research. Lupus Science \& Medicine 2021;8:e00433. doi:10.1136/ lupus-2020-000433

- Additional material is published online only. To view, please visit the journal online (http://dx.doi.org/10.1136/ lupus-2020-000433).

Received 10 August 2020 Revised 28 January 2021 Accepted 29 January 2021

Check for updates

\section{(c) Author(s) (or their} employer(s)) 2021. Re-use permitted under CC BY-NC. No commercial re-use. See rights and permissions. Published by BMJ.

For numbered affiliations see end of article.

Correspondence to

Karin Tse; karinstse@gmail.com

\section{ABSTRACT}

The Addressing Lupus Pillars for Health Advancement (ALPHA) Project is a global consensus effort to identify, prioritise and address top barriers in lupus impacting diagnosis, care, treatment and research. To conduct this process, the ALPHA Project convened a multistakeholder Global Advisory Committee (GAC) of lupus experts and collected input from global audiences, including patients. In phase I, the ALPHA Project used expert interviews and a global survey of lupus experts to identify and categorise barriers into three overarching pillars: drug development, clinical care and access to care. In phase II, reported here, the GAC developed recommended actionable solutions to address these previously identified barriers through an in-person stakeholder meeting, followed by a two-round scoring process. Recommendations were assessed for feasibility, impact and timeline for implementation (FIT), where potential FIT component values were between 1 and 3 and total scores were between 3 and 9. Higher scores represented higher achievability based on the composite of the three criteria. Simplifying and standardising outcomes measures, including steroid sparing as an outcome (drug development) and defining the lupus spectrum (clinical care) ranked as the highest two priority solutions during the GAC meeting and received high FIT scores (7.67 and 7.44, respectively). Leveraging social media (access to care) received the highest FIT score across all pillars (7.86). Cross-cutting themes of many solutions include leveraging digital technology and applying specific considerations for special populations, including paediatrics. Implementing the recommendations to address key barriers to drug development, clinical care and access to care is essential to improving the quality of life of adults and children with lupus. Multistakeholder collaboration and guidance across existing efforts globally is warranted.

\section{Key messages}

What is already known about this subject?

- Lupus is a complex, heterogeneous autoimmune disease in which outcomes vary widely across the globe, with lengthy time to diagnosis, limited treatment options and recognised health disparities.

- The Addressing Lupus Pillars for Health Advancement (ALPHA) Project is a multiphase, global consensus effort that has thoughtfully engaged global lupus experts, including clinicians, researchers, industry representatives, advocacy organisations and people with lupus to identify and prioritise key barriers spanning drug development, clinical care and access to care.

What does this study add?

- The ALPHA Global Advisory Committee convened to develop strategies and recommendations to address prior outlined barriers, including simplifying and standardising outcome measures, including steroid sparing; defining the lupus spectrum; increasing understanding of social determinants of health and contributors to health disparities; and assessing and identifying gaps of current biomarker development and data sharing activities.

\section{INTRODUCTION}

\section{Background}

Systemic Lupus Erythematos (SLE, or lupus) is a complex, heterogeneous autoimmune disease with enormous multisystem impact. Despite considerable variability in outcomes, people with lupus have an overall increased risk of death. While lupus impacts people of all 


\section{Key messages}

How might this impact clinical practice?

- Large-scale, coordinated efforts to develop and implement recommendations from the ALPHA Project across global stakeholder groups have the potential to improve outcomes for people with lupus by reducing time to diagnosis, increasing availability of safe and effective treatment options, and improving access to care.

ages and races, young age at onset, non-European ancestry and lower socioeconomic status are risk factors for poorer outcomes. Minority racial/ethnic groups, including people of African ancestry, Hispanics and Asians have a significantly higher risk of death due to lupus. Geographical differences, poverty, education levels and insurance status also negatively impact lupus mortality. ${ }^{1}$ Not surprisingly, numerous healthcare access issues persist, including access to specialty care and institutions skilled in treating lupus. ${ }^{34}$ These realities contribute to significant unmet needs in care.

In contrast to other autoimmune diseases such as rheumatoid arthritis and psoriasis, there are few approved medications for lupus. Persistent challenges to understanding disease biology, defining clinical trial inclusion criteria and endpoints, developing instruments to measure changes in clinical activity and controlling background medications have posed as long-standing barriers in lupus drug development. ${ }^{5}$ Many promising therapeutic agents have failed to demonstrate efficacy over standard of care, and there are few trials that have focused on or included paediatric populations. At the same time, over 30 companies are currently investing in lupus clinical trials. ${ }^{6}$

Another pressing consideration in lupus drug development is safety. Current treatments used for lupus, including glucocorticoids and immunosuppressive treatments, are associated with significant toxicity and poor long-term outcomes. ${ }^{78}$ Many patients with lupus are treated with combination therapies and take numerous concomitant medications, making drug interactions a source of concern for patients and healthcare providers. In paediatric patients, drug metabolism differences, puberty and linear growth, and ongoing brain development are important factors that influence therapy development and drug safety.

\section{The Addressing Lupus Pillars for Health Advancement (ALPHA) Project}

The ALPHA Project is a landmark initiative to identify, prioritise and implement global strategies to address the most pressing challenges that limit progress in lupus outcomes. ALPHA brings together lupus experts from around the globe-including patients-to identify barriers impacting drug development, clinical care and access to care, along with actionable solutions to address each barrier. Phase I, during which these barriers were identified, was completed in $2019 .^{9}$ As described in this article, the goals of phase II were to confirm the barriers, identify and reach consensus on actionable solutions to each barrier, and determine preliminary steps to implement these solutions. Figure 1 summarises the phases of the ALPHA Project.

\section{ALPHA Project leadership}

The ALPHA Project is led by the Lupus Foundation of America (LFA) in collaboration with the Tufts University School of Medicine Center for the Study of Drug Development and a Global Advisory Committee (GAC) of lupus experts. The GAC, composed of the publication authors and listed in online supplemental file 1, is a diverse group of lupus patient advocates, clinicians, academic researchers and biopharmaceutical industry representatives across five countries.

\section{ALPHA Project phase I summary}

As described in Manzi et al, phase I of the ALPHA Project examined barriers to lupus diagnosis, care, treatment and research, and how these barriers impact the quality

\begin{tabular}{|c|c|c|}
\hline Identifying Barriersi & Identifying Solutions & Implementing Solutions \\
\hline $\begin{array}{l}\text { Established the Global Advisory } \\
\text { Committee (GAC) of } 13 \text { initial } \\
\text { lupus experts } \\
\text { - Identified a preliminary list of } \\
\text { barriers } \\
\text { - Interviewed } 17 \text { lupus experts, } \\
\text { including } 4 \text { GAC members, to } \\
\text { further define the barriers and } \\
\text { categorize them into three pillars: } \\
\text { drug development, clinical care, } \\
\text { access to care } \\
\text { Conducted a global online survey } \\
\text { completed by } 127 \text { lupus experts } \\
\text { about their perceptions on } \\
\text { barriers to lupus diagnosis, care, } \\
\text { treatment, and research } \\
\text { Analyzed survey results to } \\
\text { prioritize the barriers across } \\
\text { pillars }\end{array}$ & $\begin{array}{l}\text { Administered global online } \\
\text { patient survey completed by } \\
3,233 \text { people with } \\
\text { lupus/caregivers to reaffirm } \\
\text { barriers identified in Phase I } \\
\text { " Surveyed GAC on future } \\
\text { success states to be achieved by } \\
\text { addressing barriers from Phase I } \\
\text { " Held in-person GAC meeting to } \\
\text { identify and vote on actionable } \\
\text { solutions to achieve success } \\
\text { states } \\
\text { GAC members scored solutions } \\
\text { within each pillar on feasibility, } \\
\text { impact, and timeline for } \\
\text { implementation } \\
\text { Convened GAC virtually to } \\
\text { provide input on achievability of } \\
\text { potential solutions and next } \\
\text { steps for Phase III }\end{array}$ & $\begin{array}{l}\text { Appoint task force to develop } \\
\text { implementation plans for each } \\
\text { solution } \\
\text { - Identify implementation teams for } \\
\text { each solution } \\
\text { - Continue engaging lupus } \\
\text { stakeholders and community } \\
\text { partners in ALPHA }\end{array}$ \\
\hline
\end{tabular}

Figure 1 ALPHA Project phases. 
Table 1 Top three barriers in each pillar identified in phase I

\begin{tabular}{|c|c|c|}
\hline Drug development & Clinical care & Access to care \\
\hline $\begin{array}{l}\text { Lack of biomarkers to predict } \\
\text { response to drug in clinical trials }\end{array}$ & $\begin{array}{l}\text { Lack of diagnostic, predictive and } \\
\text { prognostic biomarkers for lupus }\end{array}$ & $\begin{array}{l}\text { Less effective management of lupus due to } \\
\text { social determinants of health in predominantly } \\
\text { lower socioeconomic status areas }\end{array}$ \\
\hline $\begin{array}{l}\text { Lack of user-friendly, sensitive and } \\
\text { accurate outcome measures }\end{array}$ & Lack of treatment adherence & Lack of patient access to clinical lupus experts \\
\hline $\begin{array}{l}\text { Suboptimal clinical trial design and } \\
\text { outcome measures for patients across } \\
\text { age groups }\end{array}$ & $\begin{array}{l}\text { Limited awareness and understanding } \\
\text { of lupus among non-expert medical } \\
\text { professionals }\end{array}$ & $\begin{array}{l}\text { Lack of access to medications either due to } \\
\text { lack of coverage or added cost to patients }\end{array}$ \\
\hline
\end{tabular}

of life of people with lupus. The GAC, consisting of 13 thought leaders in phase I, identified a preliminary list of barriers through a mixed-methods approach that included structured interviews and a global survey. Representatives from the Tufts University School of Medicine Center for the Study of Drug Development interviewed 4 GAC members and 13 additional non-GAC lupus experts comprising clinicians, clinical investigators, patient advocates, government representatives and people with lupus to further characterise the barriers initially outlined by the GAC. The top barriers identified by interviewees were categorised into three pillars: (1) drug development, (2) clinical care and (3) access to care.

Findings from the expert interviews informed the development of an online survey distributed to a diverse, international stakeholder audience to achieve broad consensus on the barriers as well as prioritisation. The study validated known challenges in lupus, identifying the following top barriers to improving lupus outcomes (table 1).

\section{ALPHA PROJECT PHASE II \\ Goal and activities}

The goal of phase II was to develop and prioritise proposed actionable solutions that directly address barriers identified in phase I across lupus drug development, clinical care and access to care. Phase II activities included ensuring alignment of priorities with the patient community through development, dissemination and analysis of a global online patient survey and further engagement of the GAC to develop specific recommendations for next steps to implement the identified solutions.

\section{Defining success states}

The three pillars and associated barriers identified in phase I provided a framework to generate actionable solutions in phase II. To begin this process, GAC members completed a questionnaire (included in online supplemental file 2) to provide brief and specific descriptions of a high-level 'future success state' to be achieved for each pillar by addressing the related barriers. The GAC members' responses were then consolidated into the descriptions of success states included in table 2 .

These definitions of a 'success state' were highly consistent with those collected during the in-depth interviews performed in phase I. A comparison of the barriers, pillars and definitions of success showed alignment around several key themes: (1) disease heterogeneity, (2) need for improved diagnostic tools, (3) limitations of current therapies, (4) need for broader physician education, (5) lack of treatment or trial protocol adherence and (6) rising treatment costs.

\section{Patient survey}

To further validate barriers identified by the GAC and to ensure representation of the patient voice, the ALPHA team developed and administered a 23-question global online patient and caregiver survey on the top priorities in lupus care and research. The survey questions focused on three key themes to align with the three lupus pillars: research participation (aligning with the drug development pillar), lupus diagnosis (aligning with the clinical care pillar), and managing and accessing lupus care (aligning with the clinical care and access to care pillars). The survey was administered between 16 November 2019

Table 2 Success states by pillar identified by Global Advisory Committee members in phase II

\begin{tabular}{lll}
\hline Drug development & Clinical care & Access to care \\
\hline Improved trial design across age groups & $\begin{array}{l}\text { Biomarkers to support timely and } \\
\text { accurate diagnosis }\end{array}$ & $\begin{array}{l}\text { Access to high quality, specialised care } \\
\text { regardless of location }\end{array}$ \\
$\begin{array}{l}\text { Improved outcome measures to be } \\
\text { uniformly implemented across sponsors }\end{array}$ & $\begin{array}{l}\text { Improved support programmes to } \\
\text { encourage treatment adherence } \\
\text { among patients }\end{array}$ & $\begin{array}{l}\text { Improved access to care for individuals of } \\
\text { lower socioeconomic status }\end{array}$ \\
$\begin{array}{lll}\text { Improved biomarkers to better define } \\
\text { heterogeneity and predict response to } \\
\text { investigational therapies }\end{array}$ & $\begin{array}{l}\text { Biomarkers to predict patients' } \\
\text { responses to therapies to support } \\
\text { design of treatment regimens }\end{array}$ & $\begin{array}{l}\text { Improved global access to advanced } \\
\text { diagnostics and therapies }\end{array}$ \\
\hline
\end{tabular}


and 8 December 2019 and disseminated via email by the LFA and the World Lupus Federation in English, Spanish, Korean and simplified Chinese.

A total of 3233 people completed the survey and 214 completed at least $68 \%$ of the survey. Partial responses at this cut-off level had complete answers across all three pillars and were missing only demographic responses, and thus were included in the analysis. Survey respondents included 3330 individuals with lupus and 117 caregivers of children or teenagers under the age of 18 years with lupus. Respondents from 83 countries participated in the survey. Respondents represented a broad range of lupus manifestations, races/ethnicities, countries and ages. They self-identified as either White (57\%), Hispanic/Latino (18\%), Black or African-American $(14 \%)$, or Asian $(10 \%)$. Additional information on the survey respondents is included in online supplemental file 3 .

Of the total respondents, most identified as having either SLE without nephritis $(66 \%)$ or SLE with nephritis $(25 \%)$. Fifty-nine per cent of respondents reported receiving a lupus diagnosis within a year of discussing symptoms with their doctor. Approximately 60\% of respondents reported being misdiagnosed before receiving a lupus diagnosis, with depression and anxiety the most common misdiagnoses (reported by $20 \%$ and $19 \%$, respectively).

The top reported challenges experienced by people with lupus were managing medication side effects (43\%) and lack of treatment options to relieve symptoms (30\%), indicating the priority for new safe and effective treatments. Additionally, difficulty affording care or treatment due to high out-of-pocket costs was also listed as a top concern by $27 \%$ of respondents.

Only a relatively small portion of respondents (23\%) had participated in research, including clinical trials, and most of these individuals learnt of research opportunities through their doctors (49\%). Those who reported not participating in research cited not being asked by their doctor $(41 \%)$ as the top reason for not participating. Eighty-eight per cent of respondents indicated that, at the time of the survey, they currently saw a rheumatologist for lupus, and less than half of respondents (44\%) reported disease management by a primary care physician. A lack of education and awareness about clinical trials, including addressing concerns about benefits and risks of participation, was reported as barriers by $33 \%$ of respondents. Access and eligibility were also noted as important factors to be considered in trial design. Insights from the global patient survey supported themes identified from lupus experts around top barriers.

\section{GAC meeting}

The GAC held an in-person meeting on 15-16 January 2020 in Washington, DC, to identify actionable solutions to achieve the success states outlined for drug development, clinical care and access to care. Meeting attendees included 18 GAC members, representatives from the
Tufts Center for the Study of Drug Development, staff of the LFA and members of Faegre Drinker Consulting, who led the phase II strategy and facilitated the meeting.

Attendees began the meeting by reviewing and confirming the success states developed based on their responses to the premeeting questionnaire. The meeting then followed the same set of steps for each of the three pillars:

- Review of the patient survey data related to that pillar.

- Breakout session group activities (three groups, including at least one of the following meeting participant types per group: clinician-researcher, biopharmaceutical industry, patient advocate and person with lupus):

- Identify at least one action to achieve each success state.

- Vote on the highest-priority solutions.

- Present the breakout group's proposed highestpriority solutions to all meeting participants.

- Vote by all meeting participants on the consolidated set of proposed solutions identified by each breakout group, followed by full-group voting on overall highest-priority solutions.

The structured sessions produced consensus lists of solutions for each of the three pillars as shown in table 3 .

\section{Feasibility, impact and timeline for implementation (FIT) scoring of solutions}

Following the in-person meeting, GAC members were asked to assess the priority solutions within each pillar by rating each item for its feasibility, impact and timeline for implementation (FIT) using a detailed scoring guide (online supplemental file 4). This scoring process draws on project management tools such as the Project Management Institute's Matrix for the Evaluation of Strategic Alternatives, which facilitates group decision-making by assessing different factors that contribute to a solution's achievability. Individual FIT components had potential values between 1 and 3, and each solution could receive a total composite score between 3 and 9. Higher scores represent an overall higher achievability based on the composite of the three FIT components.

The LFA programmed the FIT scoring questionnaire through Qualtrics survey software and asked GAC members to participate in two scoring rounds. Drawing from the Delphi method and to better drive consensus, the LFA shared the anonymised scores from the first round with GAC members prior to asking them to complete the second round of scoring. The total scores from round 1 and round 2 of the FIT scoring exercises are presented in table 4.

Four solutions, at least one for each pillar, received FIT scores notably higher than the others after the second round (all scoring greater than 7.00):

1. Access to care: leverage social media (7.78).

2. Drug development: simplify and standardise clinical trial outcome measures, including steroid-sparing as an outcome (7.67). 
Table 3 Ranked solutions per pillar identified by Global Advisory Committee

\begin{tabular}{|c|c|c|}
\hline Drug development & Clinical care & Access to care \\
\hline $\begin{array}{l}\text { 1. Simplify and standardise clinical trial } \\
\text { outcome measures, including steroid- } \\
\text { sparing as an outcome. } \\
\text { 2. Develop data sharing approaches } \\
\text { related to biomarkers, clinical data and } \\
\text { lab samples. } \\
\text { 3. Propel quality of life-driven studies (eg, } \\
\text { fatigue). } \\
\text { 4. Increase participant representativeness } \\
\text { in clinical trials (e.g., minority, } \\
\text { paediatric and cutaneous lupus } \\
\text { erythematosus). }\end{array}$ & $\begin{array}{l}\text { 1. Define the lupus spectrum. } \\
\text { 2. Perform longitudinal studies } \\
\text { of prognostic and diagnostic } \\
\text { biomarkers. } \\
\text { 3. Drive clinical and lab-based } \\
\text { measures for individualised } \\
\text { treatments. } \\
\text { 4. Identify and support development of } \\
\text { treatment adherence strategies that } \\
\text { work for lupus and communicate } \\
\text { them to patients and providers. }\end{array}$ & $\begin{array}{l}\text { 1. Build the case for World Health } \\
\text { Organisation (WHO) prioritisation of } \\
\text { lupus. } \\
\text { 2. Develop standardised and specialised, } \\
\text { expert-driven care pathways. } \\
\text { 3. Drive telehealth advances and } \\
\text { reimbursement, and build on current } \\
\text { infrastructures. } \\
\text { 4. Explore broader partnering. } \\
\text { 5. Leverage social media. } \\
\text { 6. Develop evidence base for } \\
\text { interventions, including standardised } \\
\text { endpoints/outcomes. } \\
\text { 7. Provide payor education and establish } \\
\text { alignment. }\end{array}$ \\
\hline
\end{tabular}

3. Clinical care: define the lupus spectrum (7.44).

4. Clinical care: identify and support the development of adherence strategies for patients with lupus and communicate them to patients, caregivers and providers (7.22).

The GAC members showed a clear consensus on the solutions for the clinical care and drug development pillars both by voting during the GAC meeting and the FIT scoring. They ranked 'defining the lupus spectrum' (clinical care) and 'simplifying and standardising clinical trial outcomes measures, including steroid-sparing as an outcome' (drug development) as the highest-priority solutions during the meeting and FIT scoring. However, prioritisation of solutions within the access to care pillar differed from the in-person meeting and FIT scoring. 'Building a case for World Health Organization (WHO) prioritisation' was ranked the highest priority during the GAC meeting, but that solution received the lowest FIT score. At the same time, the GAC members gave 'leveraging social media' the highest FIT score within the access to care pillar and among all three pillars, but ranked it as a low priority during the GAC meeting.

\section{DISCUSSION AND NEXT STEPS}

After completing two rounds of FIT scoring, the GAC members and the patient representatives convened virtually on 20 May 2020 and 17 June 2020 to provide input on the next steps to implement the top-priority solutions.

\section{Drug development}

The GAC members and patient representatives ranked 'simplifying and standardising clinical trial outcome measures, including steroid-sparing as an outcome' as the highest-priority solution for the drug development pillar during the GAC meeting and the FIT scoring process. During the in-person meeting, participants agreed that current trial outcome measures have many limitations. The heterogeneity of lupus, the wide age spectrum of affected individuals, including children, suboptimal clinical trial designs, and a lack of validated biomarkers mean many outcome measures may have limitations for regulatory decision-making. For example, the diversity of lupus manifestations means that two individuals with active disease may have non-overlapping manifestations, possibly not adequately captured by available activity scores. Addressing such variation using a single outcome measure therefore presents a significant challenge. Simplifying and standardising outcome measures could minimise confusion about which measures to use, allow comparisons between trials, and provide a diverse set of measures to evaluate the success of interventions for the various types of lupus and across adults and children with this condition. Additionally, steroid-sparing, which is often used as a secondary endpoint in clinical trials, has been shown in large cohort studies to be a clinically meaningful outcome important in all age groups to prevent long-term organ damage.

\section{Next steps}

GAC members will publish an update on the current lupus outcome measures and issue a declarative consensus statement on steroid-sparing, emphasising that steroid tapering in practice should be the goal and should be used as a secondary endpoint in clinical trials to help achieve that goal. By crystallising current thinking and expanding the evidence base on outcome measures, including steroid-sparing, GAC members provide an opportunity for the US Food and Drug Administration and other regulatory organisations to enhance the drug development process by modifying currently accepted outcome measures.

\section{Clinical care}

The GAC members and patient representatives ranked defining the lupus spectrum as their highest priority for the clinical care pillar during the GAC meeting and the FIT scoring. In phase I, the GAC began to explore conceptualising lupus as a spectrum, or umbrella, of related 


\begin{tabular}{lll}
\hline Table 4 & Total FIT scores & \\
\hline & \multicolumn{2}{l}{ Total } \\
\cline { 2 - 2 } Consensus item & Round 1 & Round 2 \\
\hline $\begin{array}{l}\text { Drug development } \\
\text { Simplify and standardise clinical } \\
\text { trial outcome measures, including } \\
\text { steroid-sparing as an outcome. }\end{array}$ & 7.28 & \\
$\begin{array}{l}\text { Increase participant } \\
\text { representativeness in clinical trials } \\
\text { (e.g., minority, paediatric and } \\
\text { cutaneous lupus erythematosus). }\end{array}$ & \\
$\begin{array}{l}\text { Propel quality of life-driven } \\
\text { studies (e.g., fatigue). }\end{array}$ & 6.676 \\
$\begin{array}{l}\text { Develop data sharing approaches } \\
\text { related to biomarkers, clinical } \\
\text { data and lab samples. }\end{array}$ & 6.00 & \\
\hline
\end{tabular}

\section{Clinical care}

$\begin{array}{lll}\text { Define the lupus spectrum. } & 6.94 & 7.44 \\ \begin{array}{l}\text { Identify and support development } \\ \text { of adherence strategies that work } \\ \text { for lupus and communicate them }\end{array} & 7.17 & 7.22 \\ \text { to patients and providers. } & & \\ \begin{array}{l}\text { Drive clinical and lab-based } \\ \text { measures for individualised }\end{array} & 6.06 & 5.89 \\ \text { treatments. } & & \\ \begin{array}{l}\text { Perform longitudinal studies } \\ \text { of prognostic and diagnostic } \\ \text { biomarkers. }\end{array} & 6.17 & 5.50 \\ \end{array}$

\begin{tabular}{lll}
\hline $\begin{array}{l}\text { Access to care } \\
\text { Leverage social media. }\end{array}$ & 7.94 & 7.78 \\
\hline $\begin{array}{l}\text { Explore broader partnering. } \\
\text { Provide payor education and }\end{array}$ & 6.71 & 6.89 \\
\hline $\begin{array}{l}\text { establish alignment. } \\
\text { Develop standardised and }\end{array}$ & 6.28 & 6.44 \\
$\begin{array}{l}\text { specialised, expert-driven care } \\
\text { pathways. }\end{array}$ & 6.44 \\
$\begin{array}{l}\text { Develop evidence base } \\
\text { for interventions, including } \\
\text { standardised endpoints/ } \\
\text { outcomes. }\end{array}$ & 6.36 & 6.00 \\
$\begin{array}{l}\text { Drive telehealth advances and } \\
\text { reimbursement, and build on } \\
\text { current infrastructures. }\end{array}$ & 6.22 & 6.00 \\
$\begin{array}{l}\text { Build the case for World Health } \\
\text { Organization (WHO) prioritisation. }\end{array}$ & 5.52 & 5.11 \\
\hline
\end{tabular}

The solutions are listed in order of highest to lowest Round 2 FIT score within each pillar.

FIT, feasibility, impact and timeline for implementation.

disorders across immune-mediated inflammatory disorders (IMIDs) (e.g., rheumatoid arthritis, antiphospholipid syndrome, Sjögren's syndrome), as well as ranging from cutaneous lupus through systemic disease. Lupus may coexist with and often presents with clinical features similar to other autoimmune diseases. ${ }^{10-12}$ Emerging science also characterises lupus as a systemic spectrum disorder, rather than as multiple single-organ diseases. ${ }^{13}$ However, misuse of the current classification criteria as diagnostic criteria has become a norm in routine practice. Therefore, development of broader diagnostic criteria better suited for clinical use across the full 'lupus spectrum' is warranted.

Next steps

GAC members will lead the development of a consensus effort to define lupus that builds on current research definitions and includes closely related IMIDs and, for example, cutaneous variants. After establishing a consensus definition, GAC members will work with other stakeholders in the global lupus community to disseminate the definition through publication and broader discussion.

\section{Access to care}

Although GAC members and the patient representatives ranked leveraging social media as a lower priority during the in-person meeting, they gave it the highest FIT score within the access to care pillar and overall. Many people with lupus already use social media such as Facebook, Twitter, online communities, blogs, Instagram and YouTube to access information and support for managing their disease. ${ }^{14}$ Social media tools are fast, widely used, accessible and low-cost options that can be optimised for broad outreach. By leveraging social media tools, lupus providers, advocacy organisations, researchers and other stakeholders can increase interaction with the lupus patient community to enable opportunities for individuals to access research opportunities, educational and self-management resources, and social support.

During the in-person meeting, meeting participants ranked 'identifying and supporting the development of successful treatment adherence strategies for people with lupus and communicating them to patients and providers' as a low priority, but this solution received the second highest FIT score within the access to care pillar. Treating lupus is a lifelong process that requires ongoing planning and communication. It is important to apply the findings from existing literature about support strategies, treatment adherence and non-adherence in lupus to everyday practice. This is especially important among populations with more limited access to care and who are more likely to be non-adherent.

GAC members and the patient representatives ranked building a case for the WHO prioritisation as the highestpriority solution within the access to care pillar during the in-person meeting, but this solution had the lowest overall FIT score. Engaging with the WHO could pave the way for globally recognised lupus standards, guidance and best practices, with substantial and far-reaching effects on access to care. However, the potential logistical difficulties of engaging with the WHO may make other solutions to improve access to care more achievable, especially in the next $1-5$ years. 


\section{Next steps}

The GAC members agreed that the set of access to care solutions needs to be refined prior to defining specific next steps. GAC members will lead an effort to (1) gain a better understanding of social determinants of health and contributors to health disparities by examining how current tools, such as the LFA registry, ${ }^{15}$ can help capture the patient experience for regulatory and coverage purposes, as well as disparities interventions, and (2) explore the unique access to care issues faced by paediatric patients.

\section{Cross-pillar initiative}

The GAC also noted that identifying and validating biomarkers could help to address overlapping barriers to both drug development and clinical care. While recommendations related to biomarkers received low FIT scores, largely due to the longer timelines for implementation, this work would still make an important impact. Biomarkers may provide better targets for drug development efforts and aid clinicians with diagnosis, monitoring disease activity and determining an appropriate care regimen for patients.

\section{Next steps}

The GAC will lead an assessment of current biomarker development and data sharing activities and identify gaps. This assessment will inform next steps to building standardised global data sharing efforts that link North American initiatives with global initiatives, where possible, and open the door for international collective research collaborations.

\section{Cross-cutting themes}

Throughout the in-person meeting discussion, it was clear that leveraging digital technology was an emergent theme in GAC recommendations across the pillars, whether for developing data sharing approaches related to biomarkers or leveraging telehealth practices to increase access to care. Additionally, each of these recommendations warrants applying specific considerations for special populations, including children and teens with lupus, as development and outcomes differ from adult populations. As lupus affects predominantly diverse people of colour and of lower socioeconomic status, special considerations for these groups are also needed.

\section{CONCLUSION}

The ALPHA Project has convened lupus experts across stakeholder groups, including people with lupus, to identify, assess, and prioritise concrete solutions to address barriers in lupus drug development, clinical care and access to care. To begin the next phase of the ALPHA Project, the GAC will appoint a task force to develop an implementation plan for the chosen solutions, including selecting teams to carry out the efforts. The ALPHA team will continue to engage broad stakeholder audiences to increase awareness and involvement with ALPHA efforts to increase adoption of implementation plans.

Lupus is a major public health challenge and the ALPHA Project represents the first global initiative to transform outcomes across the entire continuum of drug development, clinical care and access to care by bringing scientific leaders and the lupus patient community together. Implementation of each solution will require substantial resources and a coordinated series of activities across stakeholders. Such a global concerted effort that includes a strong patient voice alongside clinicians, academics and industry partners will be essential for its success.

\section{Author affiliations}

${ }^{1}$ Research, Lupus Foundation of America Inc, Washington, District of Columbia, USA ${ }^{2}$ Faegre Drinker Consulting, Faegre Drinker Biddle and Reath LLP, Washington, DC, USA

${ }^{3}$ Lupus and Allied Diseases Association, Inc, Verona, New York, USA

${ }^{4}$ Rheumatology, Hanyang University Seoul Hospital, Seongdong-gu, Seoul, South Korea

${ }^{5} \mathrm{NIHR}$ Manchester Biomedical Research Centre, Manchester, UK

${ }^{6}$ Musculoskeletal and Dermatological Sciences, The University of Manchester, Manchester, UK

${ }^{7}$ Autoimmune and Rare Disease Division, Mallinckrodt Pharmaceuticals Specialty Brands, Bedminster, New Jersey, USA

${ }^{8}$ Medicine, Brigham and Women's Hospital, Boston, Massachusetts, USA

${ }^{9}$ Aurinia Pharmaceuticals Inc, Victoria, British Columbia, Canada

${ }^{10}$ Rheumatology and Clinical Immunology, Charite University Hospital Berlin, Berlin, Germany

${ }^{11}$ Patient Representative, Riverdale, Maryland, USA

${ }^{12}$ Medical Center, University of California San Diego, La Jolla, California, USA

${ }^{13}$ EMD Serono Research and Development Institute, Billerica, Massachusetts, USA

${ }^{14}$ Medicine, Allegheny Health Network, Pittsburgh, Pennsylvania, USA

${ }^{15}$ Rheumatology, Monash University, Clayton, Victoria, Australia

${ }^{16}$ Internal Medicine/Nephrology, The Ohio State University Wexner Medical Center, Columbus, Ohio, USA

${ }^{17}$ Pediatrics, Duke University Medical Center, Durham, North Carolina, USA

${ }^{18} \mathrm{GlaxoSmithKline} \mathrm{USA,} \mathrm{Philadelphia,} \mathrm{Pennsylvania,} \mathrm{USA}$

${ }^{19}$ Dermatology, University of Pennsylvania, Philadelphia, Pennsylvania, USA

${ }^{20}$ Corporal Michael J Crescenz VA Medical Center, Philadelphia, Pennsylvania, USA

${ }^{21}$ Patient Representative, Richmond, Virginia, USA

${ }^{22}$ Faegre Drinker Consulting, Faegre Drinker Biddle and Reath LLP, Indianapolis, Indiana, USA

${ }^{23}$ Center for the Study of Drug Development, Tufts University School of Medicine, Boston, Massachusetts, USA

Twitter Kathleen Arntsen @kathleenarntsen and lan N Bruce @Lupusdoc

Acknowledgements The authors thank the Global Advisory Committee members, the in-person meeting participants, including global collaboration presenter Dr. Tim Coetzee of the National Multiple Sclerosis Society, and the individuals with lupus and caregivers who participated in the global survey for their leadership in phase II of the Addressing Lupus Pillars for Health Advancement Project.

Contributors All authors contributed to the discussions and data interpretation contained in this paper and provided input on the manuscript and approved its final version. SS, KT and LB contributed to the initial manuscript drafting and finalisation. KT contributed to patient and feasibility, impact and timeline (FIT) scoring survey drafting and finalisation. KT and YP contributed to patient survey data analysis. DZ, LB, SS and TF contributed to overall phase II strategies and execution, including the critical review of patient survey, moderation of Global Advisory Committee (GAC) discussions before, during and after the in-person GAC meeting, and drafting criteria for FIT scoring. LMH oversaw and approved all research efforts.

Funding The Addressing Lupus Pillars for Health Advancement Project was launched in partnership with founding partner EMD Serono Research \& Development Institute, Inc. (a business of Merck KGaA, Darmstadt, Germany) 
and through additional support by GlaxoSmithKline. Aurinia Pharmaceuticals and Mallinckrodt Pharmaceuticals provided additional sponsorship.

Competing interests SCR is an employee of the Lupus Foundation of America (LFA). SS, LB, TF and DZ are consultants of Faegre Drinker Consulting, a division of Faegre Drinker Biddle \& Reath, a law and consulting firm that represents patient advocacy organisations and sponsors developing drugs. INB receives grant/ research support from Genzyme Sanofi, GSK and UCB; is a consultant of Eli Lilly, AstraZeneca, UCB, Iltoo and Merck Serono; and affiliated with speakers bureaus for UCB and AstraZeneca. EC-S is an employee of Mallinckrodt (former). KHC receives grant/research support from Merck and is a consultant of AstraZeneca. $\mathrm{BD}$ is an employee of Aurinia (former). TD receives grant/research support from Janssen, Novartis, Roche and UCB; is a consultant of Abbvie, Celgene, Eli Lilly, Roche, Janssen and EMD; and affiliated with speakers bureaus for Eli Lilly, Roche, Samsung and Janssen. KK receives grant/research support from UCB, Novartis and Resolve; and is a consultant of AstraZeneca, Viela Bio, Genentech/Roche, Biogen, Iltoo, GSK, BMS, Janssen, Abbvie, Amgen, Eli Lilly, Kyowa Kirin, Equillium Bio and Celgene. AHK is an employee of EMD Serono. EFM receives grant/research support from AstraZeneca, BMS, Eli Lilly, GSK, Janssen and Merck-Serono; is a consultant of AbbVie, Amgen, AstraZeneca, Biogen, BMS, Eli Lilly, GSK, Janssen, Neovacs and Sandoz; and is affiliated with speaker bureaus for AstraZeneca and Novartis. BHR is a consultant for GSK, Aurinia, AstraZeneca, Novartis, Alexion and BMS. LES receives grant/research support from Sobi, BMS, CARRA Inc.; is a consultant of Aurinia, UCB (DSMB), Sanofi (DSMB) and Sobi. VPW receives grant/research support from Biogen, Celgene, Gilead, Janssen and Viela; and is a consultant of Biogen, Gilead, Janssen, Abbvie, GSK, Resolve, AstraZeneca, Amgen, Eli Lilly, EMD Serono, BMS, Viela and Kyowa Kirin. JMVF is a shareholder and employee of GSK (former). KT and LMH are employees of the LFA (former). SE and AWD are LFA patient ambassadors.

Patient and public involvement statement Lupus patient representatives and advocacy organisation representatives have been included in all steps of the Addressing Lupus Pillars for Health Advancement Project, including serving on the Global Advisory Committee (GAC). Results from a patient survey, which was developed with the GAC and distributed by patient advocacy and support groups to over 3000 people with lupus and caregivers, informed discussion of recommendations during the in-person meeting. Patient representatives were involved in the in-person meeting, actively participating in discussion, selection of top action items, subsequent feasibility, impact and timeline scoring activities and GAC calls, and providing critical review of this publication.

Patient consent for publication Not required.

Ethics approval The Advarra Institutional Review Board (IRB) determined the Addressing Lupus Pillars for Health Advancement patient survey to be exempt from IRB oversight.

Provenance and peer review Not commissioned; externally peer reviewed. Data availability statement Data are available upon reasonable request.

Supplemental material This content has been supplied by the author(s). It has not been vetted by BMJ Publishing Group Limited (BMJ) and may not have been peer-reviewed. Any opinions or recommendations discussed are solely those of the author(s) and are not endorsed by BMJ. BMJ disclaims all liability and responsibility arising from any reliance placed on the content. Where the content includes any translated material, BMJ does not warrant the accuracy and reliability of the translations (including but not limited to local regulations, clinical guidelines, terminology, drug names and drug dosages), and is not responsible for any error and/or omissions arising from translation and adaptation or otherwise.
Open access This is an open access article distributed in accordance with the Creative Commons Attribution Non Commercial (CC BY-NC 4.0) license, which permits others to distribute, remix, adapt, build upon this work non-commercially, and license their derivative works on different terms, provided the original work is properly cited, appropriate credit is given, any changes made indicated, and the use is non-commercial. See: http://creativecommons.org/licenses/by-nc/4.0/.

ORCID iDs

Karin Tse http://orcid.org/0000-0003-4992-8590

Thomas Dörner http://orcid.org/0000-0002-6478-7725

Sandra C Raymond http://orcid.org/0000-0003-1778-8095

\section{REFERENCES}

1 Singh RR, Yen EY. Sle mortality remains disproportionately high, despite improvements over the last decade. Lupus 2018;27:1577-81.

2 Carter EE, Barr SG, Clarke AE. The global burden of SLE: prevalence, health disparities and socioeconomic impact. Nat Rev Rheumatol 2016;12:605-20.

3 Gillis JZ, Yazdany J, Trupin L, et al. Medicaid and access to care among persons with systemic lupus erythematosus. Arthritis Rheum 2007:57:601-7.

4 Demas KL, Costenbader KH. Disparities in lupus care and outcomes. Curr Opin Rheumatol 2009;21:102-9.

5 The Lewin Group Inc. Overcoming barriers to drug development in lupus, 2009. Available: https://www.lupus.org/s3fs-public/ documents/Overcoming_Barriers_to_Drug_Development_in_Lupus. pd

6 Clinicaltrials.Gov, 2019. Available: https://clinicaltrials.gov/ [Accessed 21 Feb 2019]

7 Apostolopoulos D, Morand EF. It hasn't gone away: the problem of glucocorticoid use in lupus remains. Rheumatology 2017;56:i114-22.

8 Tian J, Luo Y, Wu H, et al. Risk of adverse events from different drugs for SLE: a systematic review and network meta-analysis. Lupus Sci Med 2018;5:e000253.

9 Manzi S, Raymond S, Tse K, et al. Global consensus building and prioritisation of fundamental lupus challenges: the ALPHA project. Lupus Sci Med 2019;6:e000342.

10 Lockshin MD, Levine AB, Erkan D. Patients with overlap autoimmune disease differ from those with 'pure' disease. Lupus Sci Med 2015;2:e000084.

11 Lorber M, Gershwin ME, Shoenfeld Y. The coexistence of systemic lupus erythematosus with other autoimmune diseases: the kaleidoscope of autoimmunity. Semin Arthritis Rheum 1994;24:105-13.

12 Jury EC, D'Cruz D, Morrow WJ. Autoantibodies and overlap syndromes in autoimmune rheumatic disease. J Clin Pathol 2001;54:340-7.

13 Merrill JT. Connective tissue diseases: is SLE many single-organ diseases or an overlapping spectrum? Nat Rev Rheumatol 2015;11:385-6.

14 Wheeler LM, Pakozdi A, Rajakariar R, et al. 139 Moving with the times: social media use amongst lupus patients. Rheumatology 2018:57.

15 Lupus Foundation of America. Research Accelerated by You (RAY). Available: https://www.lupus.org/research/enroll-in-a-lupus-registry 